\title{
anatomy
}

Original Article

www.anatomy.org.tr

Received: October 28, 2018; Accepted: December 5, 2018

doi:10.2399/ana.18.075

\section{Scapular glenopolar angle in anterior shoulder dislocation cases}

\author{
Özhan Pazarcı, Nazım Aytekin, Seyran Kılınç, Hayati Öztürk \\ Department of Orthopaedics and Traumatology, School of Medicine, Cumburiyet University, Sivas, Turkey
}

\begin{abstract}
Objectives: The aim of this study was to assess the glenoid with glenopolar angle measurements in cases with anterior shoulder dislocation and controls.

Methods: The glenopolar angle was measured retrospectively on direct radiographs of patients with shoulder dislocation $(n=60)$, and a control group $(n=42)$.

Results: The glenopolar angle of patients with anterior shoulder dislocation showed an anatomical difference, being significantly lower in anterior shoulder dislocation cases compared to the control group; $32.31 \pm 2.01$ and $34.5 \pm 2.32$, respectively $(\mathrm{p}<0.001)$.
\end{abstract}

Conclusion: The glenopolar angle, and thus the glenoid alignment is a possible risk factor and should be considered during assessment and management of these cases.

Keywords: glenoid; glenopolar angle; shoulder dislocation

Anatomy 2018;12(3):124-127 @2018 Turkish Society of Anatomy and Clinical Anatomy (TSACA)

\section{Introduction}

The shoulder joint is the most mobile joint in the body. This movement is mainly due to the anatomy of the humerus head and the glenoid. The glenohumeral joint is the most frequently dislocated joint. ${ }^{[1]}$ Anterior dislocation is most commonly observed, and there is a high risk of recurrence. ${ }^{[2]}$ The shoulder has a tendency to dislocate after trauma, experienced generally in abduction and external rotation positions. The recurring dislocation rates reduce after arthroscopic treatment, but this situation is still a problem. ${ }^{[2]}$ Maintenance of the glenohumeral joint association is linked to the dynamic and static stabilizers of the shoulder. The roles of capsuloligamentous structures and dynamic muscle balance in shoulder stability is well-defined in the literature..$^{[3]}$ However, there are very few studies on the importance of glenopolar angle (GPA).

GPA is the angle formed by the intersection of the line joining the most caudal and most cranial points of the glenoid cavity and the line joining the most cranial point of the glenoid cavity to the most caudal point of the scapula body. ${ }^{[4,5]}$ GPA is normally used to measure rotational sequence disorders of the glenoid in scapula fractures on anteroposterior radiographs. ${ }^{[6]}$ In this study, GPA was investigated on direct radiographs of anterior shoulder dislocation cases for the first time with an aim to assess the glenoid with GPA measurements in cases with anterior shoulder dislocation.

\section{Materials and Methods}

The study included a total of 140 adult patients admitted to Department of Orthopaedics and Traumatology, School of Medicine, Cumhuriyet University from 2013 to 2015.70 patients were with anterior shoulder dislocation, and the remaining 70 had shoulder pain, but no dislocation or any other shoulder pathology during examinations. Patient information was retrospectively investigated. The age, side, gender and demographic information of patients were noted.

The same senior orthopedic surgeon and the same resident examined all AP shoulder radiographs. Radiographs of Group 1 patients were taken after reduction of shoulder 
dislocation. Patients with true shoulder AP view were included in the evaluation, and radiographs of bad positioning and rotation were excluded from the study. Additionally, patients with insufficient file information were excluded. Group 1 comprised 60 and Group 2 comprised 42 cases for GPA measurements (Table 1). GPA measurements were made using the hospital PACS system (Medipacs ${ }^{\circledR} \mathrm{v}$ 3.8.5.1). In the system, the angle between the line from the most caudal to the most cranial points of the glenoid cavity and the line from the most cranial point of the glenoid cavity to the most caudal point of the scapula body were calculated on true AP shoulder radiographs (Figure 1).

The study was approved by the ethics committee of the School of Medicine of Cumhuriyet University. Analysis of data was made using the Statistical Package for Social Sciences (SPSS for Windows, version 22.0, Armonk, NY, USA). Data were given as percentage, frequency and the mean. The normality test of the GPA data was examined using the Kolmogorov-Smirnov test. The distribution of the variable was calculated to be normal $(p=0.2)$. Mean differences of GPA values were examined by Student's t-test. The mean difference between groups was investigated using Mann-Whitney $U$ test. The normality test for age was not appropriate $(\mathrm{p}=0.007)$.
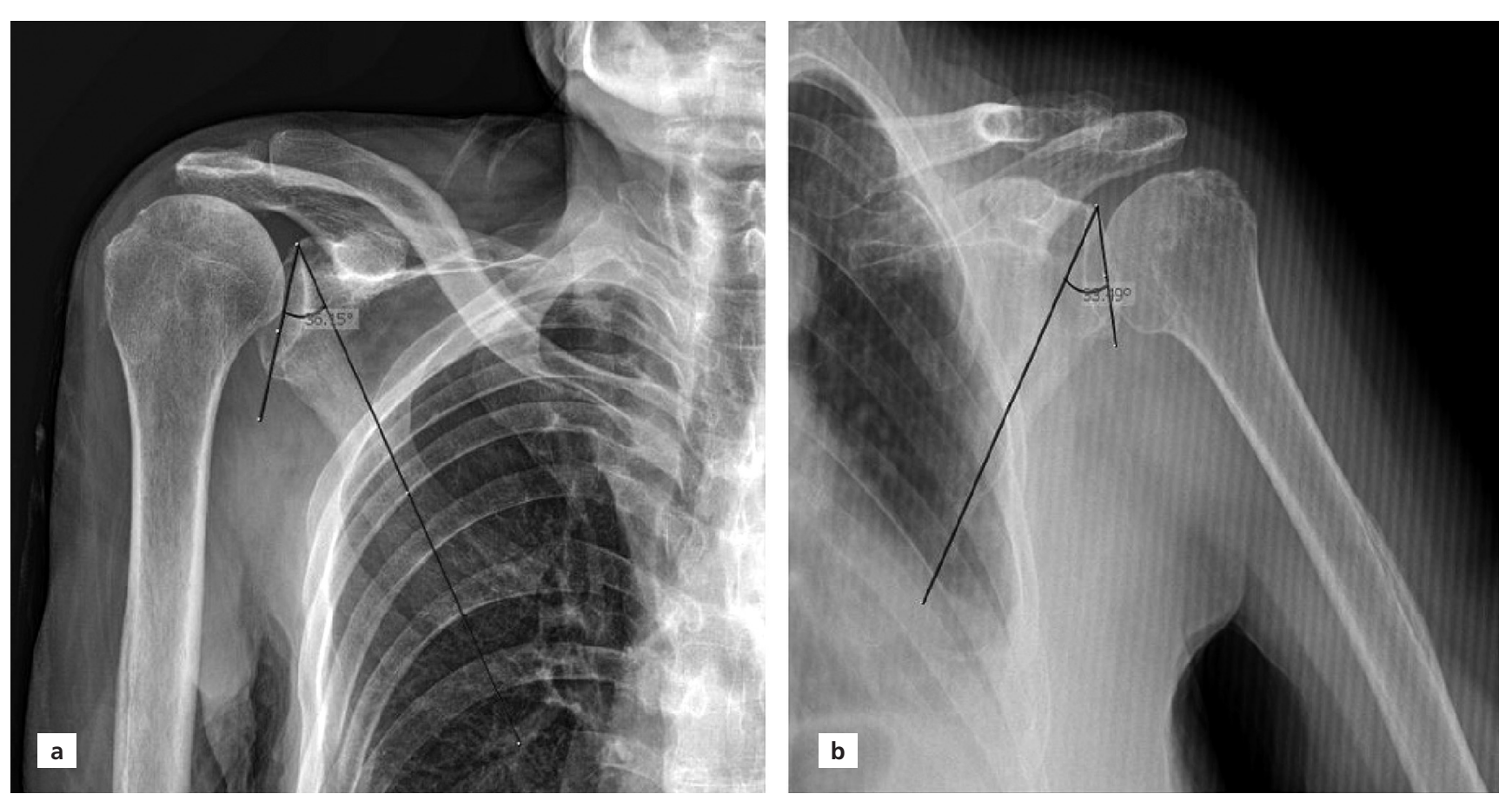

Figure 1. (a) Glenopolar angle (GPA) measurement of the angle between the line joining the most caudal and most cranial points of the glenoid cavity and the line from the most cranial point of the glenoid cavity to the most caudal point of the scapula body in a Group 2 patient; (b) GPA measurement in a Group 1 patient.

Table 1

The distribution of groups, gender, sides and accompanying shoulder injuries.

\begin{tabular}{llcc}
\hline & Category & $\mathbf{n}$ & $\%$ \\
\hline \multirow{2}{*}{ Groups } & Group 1 & 60 & 58.8 \\
& Group 2 & 42 & 41.2 \\
\hline Side & Right & 55 & 53.9 \\
& Left & 47 & 46.1 \\
\hline \multirow{2}{*}{ Gender } & Male & 56 & 54.9 \\
& Female & 46 & 45.1 \\
\hline Accompanying shoulder injury & No & 54 & 90 \\
& Yes & 6 & 10 \\
\hline
\end{tabular}

\section{Results}

The results from a total of 102 patients were assessed. The mean age of 60 patients in Group 1 was 45.68 years (min: 18, max: 85). The mean age of 42 patients in Group 2 was 47.57 years (min: 18, max: 83 ). There was no significant difference between age groups $(\mathrm{p}=0.754)$. The mean follow-up duration for Group 1 patients was 23.46 months. Six patients had accompanying shoulder injuries, including three patients with rotator cuff injury, two patients with 
fracture of the greater tubercle of the humerus, and one patient with proximal humerus fracture. These injuries did not involve the glenoid and, therefore, these six patients were not excluded from the study.

The distribution of gender for patients was 34 males and 26 females in Group 1, and 22 males and 20 females in Group 2. Table 1 shows the distribution of groups, age and sides.

The comparison of GPA by groups, gender and sides is shown in Table 2. The GPA in Group 1 was measured $32.31 \pm 2.01$, while it was $34.5 \pm 2.32$ in Group $2(\mathrm{p}<0.001)$ (Figure 2). There was no significant difference between males and females ( $p>0.05)$.

\section{Discussion}

The most important finding in this study was that the GPA of patients with anterior shoulder dislocation was significantly low. To our knowledge, this is the first study to investigate the change in GPA with direct radiography in dislocation cases. Glenoid alignment should be considered in anterior shoulder dislocation cases. Previous studies reported glenoid corrective osteotomy was superior to conservative treatment for patients with posterior instability. ${ }^{[7]}$ There is no data on the benefit of corrective osteotomy for anterior stability in the literature. However, there are studies showing a correlation between success rate of prosthesis and stability with the position of the glenoid component in total shoulder prosthesis. ${ }^{[8]}$ A study comprising 128 patients with anterior shoulder instability and a control group of 130 cases investigated the glenoid version and inclination. They concluded that glenoid alignment was a risk factor for anterior shoulder instability and emphasized that care must be taken related to this for recurrent instability treatment. ${ }^{[9]}$ These studies emphasized the effect of glenoid anatomy on shoulder stability. According to our results, GPA measurements on direct radiographs of anterior shoulder dislocation cases will provide rapid information for assessment of glenoid anatomy to orthopedists.

GPA was first described by Bestard et al., ${ }^{[4]}$ The use of this angle to assess scapula neck fractures. ${ }^{[10]}$ and later gained popularity as a surgical treatment criterion for scapula neck and body fractures. ${ }^{[1,12]}$

There is no consensus for the optimal radiological technique to measure GPA or the standard values of GPA in the literature. ${ }^{[13]}$ GPA can be measured directly on cadaver specimens, 3D scapula reconstructions, Neer view $\mathrm{X}$-ray images, AP shoulder or AP chest radiographs. ${ }^{[13]} \mathrm{In}$ this study, GPA measurement was performed on true (Grashey) AP shoulder radiographs. In the literature, there are studies with measurements made on different
Table 2

The comparison of GPA (mean \pm SD) by groups, gender and sides using Student's t-test.

\begin{tabular}{lllll}
\hline & Category & $\mathbf{n}$ & Mean \pm SD & p-value \\
\hline \multirow{2}{*}{ Groups } & Group 1 & 60 & $32.31 \pm 2.01$ & \\
& Group 2 & 42 & $34.5 \pm 2.32$ & $<0.001$ \\
\hline \multirow{2}{*}{ Side } & Right & 55 & $33.21 \pm 2.37$ & \multirow{2}{*}{0.996} \\
& Left & 47 & $33.21 \pm 2.44$ & \\
\hline \multirow{2}{*}{ Gender } & Male & 56 & $33.15 \pm 2.17$ & \multirow{2}{*}{0.769} \\
& Female & 46 & $33.29 \pm 2.65$ & \\
\hline
\end{tabular}

imaging views. ${ }^{[1,15]}$ The GPA angle value changes depending on the measurement method. Of these, 3D CT reconstruction, Neer 1 images and cadaver bone specimens provide similar results. AP shoulder and chest radiographs provide lower values compared to these measurements. ${ }^{[14]}$

There are other studies in the literature that assessed glenoid anatomy. For example, Peter et al ${ }^{[16]}$ investigated the correlation between glenoid inclination and rotator cuff tears. ${ }^{[16]}$ Gregory et al. ${ }^{[17]}$ investigated the correlation between greater tuberosity angle and rotator cuff tears. Maximilian et al.$^{[18]}$ emphasized the importance of glenoid morphology in instability arthropathy. The above studies emphasize the importance of glenoid anatomy similar to our study. Additionally, an advantage of our study is that information on the glenoid was obtained with GPA measurements on direct radiographs, without advanced tests like MR or 3D CT. A difference of $2.5^{\circ}$ was observed between the groups (Figure 2). This was statistically significant $(\mathrm{p}>0.05)$. GPA can easily be evaluated with $\mathrm{X}$-ray

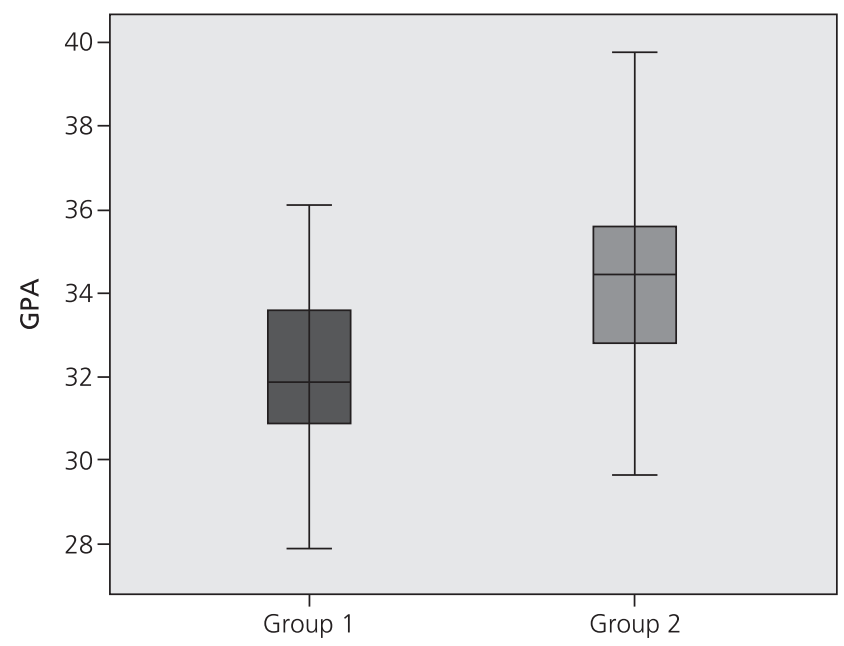

Figure 2. Box plot chart showing the means of GPAs. 
in cases of shoulder dislocation. The clinical significance of low GPA is that, this can give the orthopedic surgeon a quick idea about the glenoid.

This study has some limitations. Control group radiographs were chosen from patients admitted to the general orthopedic clinic with shoulder pain. This sample may not be representative of the normal healthy population and may potentially be biased. However, only those with no pathology identified on radiography or examination were included in the control group. Although the GPA was significantly different between the groups, it is difficult to definitively determine whether our findings are clinically significant or not, because other factors may affect the risk of dislocation. Risk factors for patients with glenohumeral instability were described previously. ${ }^{[19]}$ GPA measurements provide information about the nonmodifiable risk factor of glenoid morphology.

\section{Conclusion}

The GPA of patients with anterior shoulder dislocation was significantly low compared to the control group, showing an anatomical difference for cases with anterior shoulder dislocation. Should be considered in the assessment and management of these cases.

\section{References}

1. Owens BD, Campbell SE, Cameron KL. Risk factors for anterior glenohumeral instability. Am J Sports Med 2014;42:2591-6.

2. Peltz CD, Baumer TG, Mende V, Ramo N, Mehran N, Moutzouros V, Bey MJ. Effect of arthroscopic stabilization on in vivo glenohumeral joint motion and clinical outcomes in patients with anterior instability. Am J Sports Med 2015;43:2800-8.

3. Lugo R, Kung P, Ma CB. Shoulder biomechanics. Eur J Radiol 2008;68:16-24.

4. Bestard EA, Schvene HR, Bestard EH. Glenoplasty in management of recurrent shoulder dislocation. Contemp Orthop 1986;12:47-55.

5. Tuček M, Naňka O, Malík J, Bartoníček J. The scapular glenopolar angle: standard values and side differences. Skeletal Radiol 2014;43: 1583-7.

6. Wijdicks CA, Anavian J, Hill BW, Armitage BM, Vang S, Cole PA. The assessment of scapular radiographs: analysis of anteroposterior radiographs of the shoulder and the effect of rotational offset on the glenopolar angle. Bone Joint J 2013;95-B:1114-20.

7. Lacheta L, Singh TSP, Hovsepian JM, Braun S, Imhoff AB, Pogorzelski J. Posterior open wedge glenoid osteotomy provides reliable results in young patients with increased glenoid retroversion and posterior shoulder instability. Knee Surg Sports Traumatol Arthrosc 2019;27:299-304.

8. Nyffeler RW, Sheikh R, Atkinson TS, Jacob HAC, Favre P, Gerber C. Effects of glenoid component version on humeral head displacement and joint reaction forces: an experimental study. J Shoulder Elbow Surg 2006;15:625-9.

9. Hohmann E, Tetsworth K. Glenoid version and inclination are risk factors for anterior shoulder dislocation. J Shoulder Elbow Surg 2015;24:1268-73.

10. Romero J, Schai O IA. Scapular neck fracture: the influence of permanent malalignment of the glenoid neck on clinical outcome. Arch Orthop Trauma Surg 2001;121:313-6.

11. Cole PA, Hill BW. Scapula fracture. In: Obremskey WT, Sethi MK, Jahangir AA, editors. Orthopaedic traumatology: an evidence based approach. New York (NY): Springer; 2013. p. 71-86.

12. Bozkurt M, Can F, Kirdemir V, Erden Z, Demirkale I, Başbozkurt $M$. Conservative treatment of scapular neck fracture: the effect of stability and glenopolar angle on clinical outcome. Injury 2005;36: 1176-81.

13. Tucek M, Nanka O, Malik J, Bartonicek J. The scapular glenopolar angle: standard values and side differences. Skeletal Radiol 2014;43:1583-7.

14. Ohl X, Billuart F, Lagacé PY, Gagey O, Hagemeister N, Skalli W. 3D morphometric analysis of 43 scapulae. Surg Radiol Anat 2012;34:447-53.

15. Anavian J, Conflitti JM, Khanna G, Guthrie ST, Cole PA. A reliable radiographic measurement technique for extra-articular scapular fractures. Clin Orthop Relat Res 2011;469:3371-8.

16. Chalmers PN, Beck L, Granger E, Henninger H, Tashjian RZ. Superior glenoid inclination and rotator cuff tears. J Shoulder Elbow Surg 2018;27:1444-50.

17. Cunningham G, Nicodème-Paulin E, Smith MM, Holzer N, Cass B, Young AA. The greater tuberosity angle: a new predictor for rotator cuff tear. J Shoulder Elbow Surg 2018;27:1415-21.

18. Haas M, Plachel F, Wierer G, Heuberer P, Hoffelner T, Schulz E, Anderl W, Moroder P. Glenoid morphology is associated with the development of instability arthropathy. J Shoulder Elbow Surg 2018; pii: S1058-2746(18)30700-6. doi: 10.1016/j.jse.2018.09.010

19. Cameron KL, Mauntel TC, Owens BD. The epidemiology of glenohumeral joint instability: incidence, burden, and long-term consequences. Sports Med Arthrosc Rev 2017;25:144-9.

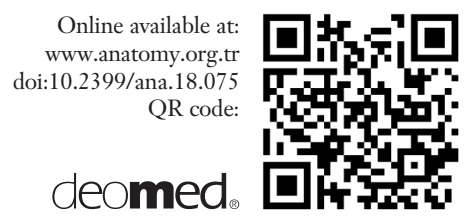

Correspondence to: Özhan Pazarcı, MD

Department of Orthopaedics and Traumatology, School of Medicine,

Cumhuriyet University, 58140, Sivas, Turkey

Phone: +90 5346819045

e-mail: dr.pazarci@gmail.com

Conflict of interest statement: No conflicts declared.

This is an open access article distributed under the terms of the Creative Commons Attribution-NonCommercial-NoDerivs 3.0 Unported (CC BY-NCND3.0) Licence (http://creativecommons.org/licenses/by-nc-nd/3.0/) which permits unrestricted noncommercial use, distribution, and reproduction in any medium, provided the original work is properly cited. Please cite this article as: Pazarcı Ö, Aytekin N, Kılınç S, Öztürk H. Scapular glenopolar angle in anterior shoulder dislocation cases. Anatomy 2018;12(3):124-127. 